\title{
EFFECTIVE USE OF ROTARY FURNACE SHELL HEAT
}

\author{
Julius Lisuch*, Dusan Dorcak, Jan Spisak
}

\author{
Workplace for developing and implementing raw materials extraction and treatment, Technical University of \\ Kosice, Nemcovej 32, 04002 Kosice, Slovak Republic \\ * corresponding author: julius.lisuch@tuke.sk
}

\begin{abstract}
A significant proportion of the total energy expenditure for heat treatment of raw materials ends up as heat losses through the shell of the rotary furnace. Currently, the waste heat is not used in any way and escapes into the environment. A controlled cooling system for the rotary furnace shell (CCSRF) is a new solution integrated into the technological process aimed at reducing the heat loss of the furnace shell. Simulations and experiments how the effect of controlled cooling of the shell on the operation of the rotary furnace. The proposed solution is cost-effective and operationally undemanding.
\end{abstract}

KEYWORDS: rotary furnace, furnace, magnesite, control shell cooling, shell.

\section{INTRODUCTION}

The heat losses in rotary furnaces account for as much as $60 \%$ according to the heat balance of the total heat supplied to the workspace. Due to its temperature potential the use of this heat for technological purposes is limited to low-temperature processes, such as drying of materials. The heat loss for direct use in the firing process of magnesite clinker in the form of reduced losses by the furnace shell and preheated combustion air is much greater. Such use will reduce fuel consumption for heating and will also increase the quality of the clinker burning. The aim of the analysis conducted here is to acquire knowledge of the system for controlled cooling of a rotary furnace shell, to determine its impact on the work of the rotary furnace, and to find optimal conditions for making use of it.

\section{ROTARY FURNACE}

Rotary furnaces are continuously working furnaces. They are used in many branches of industry and in various technologies, such as the cement industry (cement clinker burning, lime production), the refractory materials industry (magnesite clinker burning, dolomite clinker and fireclay shales). They are also used in the production of pearlite and caustic magnesite for burning below $1000^{\circ} \mathrm{C}$, in preparing ores for the iron industry, burning pellets for blast furnaces and steel mills, roasting sulphide ores, oxidizing roasting, magnetizing roasting, drying, and for drying refractory clays and sands. Rotary furnaces are cylindrical in shape with a diameter of $1-7 \mathrm{~m}$ and with a length 20-120 $\mathrm{m}$ and more, stored horizontally under a slight inclination of $2-6 \%$ (Fig. 11).

The batch and the fuel are usually fed into the furnace from the opposite ends. The furnace operates continuously in countercurrent. As a result of the inclination of the furnace and its rotation, the batch passes through the furnace with a spiraling motion.

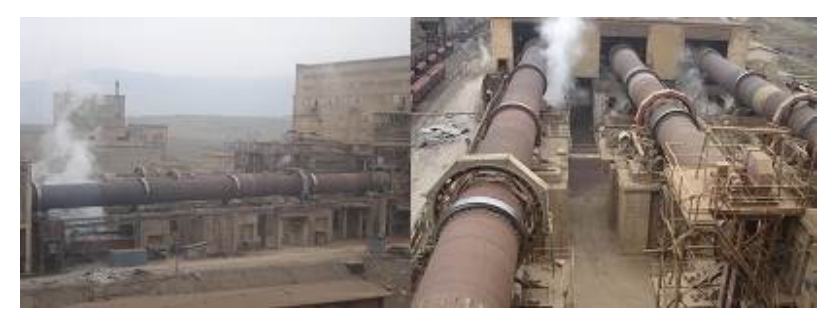

FiguRE 1. Rotary furnaces at SMZ Jelsava, a.s. for magnesite thermal treatment [1].

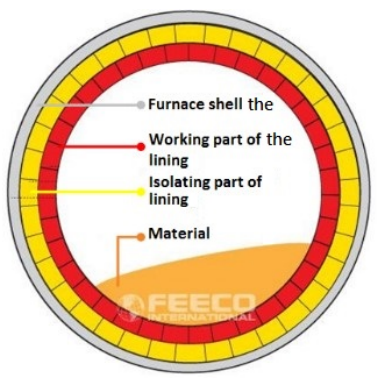

Figure 2. Composition of the lining of a rotary furnace 3 .

Co-stream movement of the combustion gases and the batch is especially used for drying. The furnace consists of a steel shell, a lining, supporting equipment, a propulsion device, towing heads (a charging installation, cold) and the cooler. In addition, the furnace may have a cross-poking device, heat exchangers, or special equipment for feeding solid and gaseous substances into the individual zones of the furnace by the holes in the shell and lining. A preheating device for the batch is often used before the furnace. The shell is lined with fireclay, magnesia, high alumina fittings or bricks (Figure 2) 2].

One of the key aspects of the operation of industrial furnaces is heat exchange. Heat exchange in the working space of the furnace is divided into:

- external heat exchange - heat transfer from the 


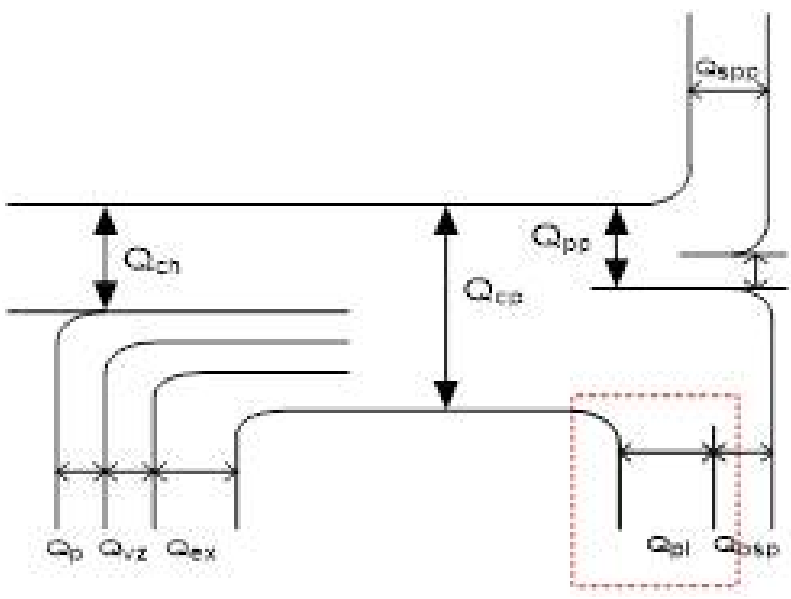

Figure 3. Sankeyov diagram 4].

flue gas and the walls for the batch,

- movement of heat inside the batch.

Both ways are contingent and are related to each other [4, 5].

\subsection{Heat losses of Rotary furnaces}

Heat release consists mainly of (Figure 3):

- workspace losses,

- outgoing flue gas losses,

- heat losses through the furnace shell.

The heat balance is described by equations 446 :

$$
\begin{gathered}
Q_{\mathrm{TB}}=Q_{\mathrm{TE}}, \\
Q_{\mathrm{CHH}}+Q_{\mathrm{HPA}}+Q_{\mathrm{HPF}}+Q_{\mathrm{EXN}}= \\
=Q_{\mathrm{HW}}+Q_{\mathrm{UH}}+Q_{\mathrm{FL}}+Q_{\mathrm{OFG}}+Q_{\mathrm{FHL}},
\end{gathered}
$$

where $Q_{\mathrm{TB}}$ is total brought heat [W], $Q_{\mathrm{TE}}-$ total exhaust heat [W], $Q_{\mathrm{CHH}}$ - chemical heat of fuel [W], $Q_{\mathrm{HPA}}$ - heat of preheated air [W], $Q_{\mathrm{HPF}}$ - heat of preheated fuel [W], $Q_{\mathrm{EXN}}$ - heat involving exothermic and endothermic reactions in the furnace area [W], $Q_{\mathrm{HW}}$ - heat of the workspace [W], $Q_{\mathrm{UH}}$ - useful heat necessary for material heating [W], $Q_{\mathrm{FL}}$ - furnace workspace heat loss [W], $Q_{\mathrm{OFG}}$ - outgoing flue gas heat loss [W], $Q_{\mathrm{FHL}}$ - furnace shell heat loss [W].

The heat removed from the furnace can be divided into:

- useful heat $Q$ - the heat that is needed for heating a batch (endothermic reactions, etc.);

- heat losses $Q$ - consisting of heat loss:

$\triangleright$ through the furnace openings (doors),

$\triangleright$ accumulated in the lining,

$\triangleright$ by radiation through the openings,

$\triangleright$ cooling water,

$\triangleright$ coming out of the material (in the product),

$\triangleright$ through the furnace shell $(\mathrm{Qpl})$ - led through the walls and into the furnace casing (furnace shell),

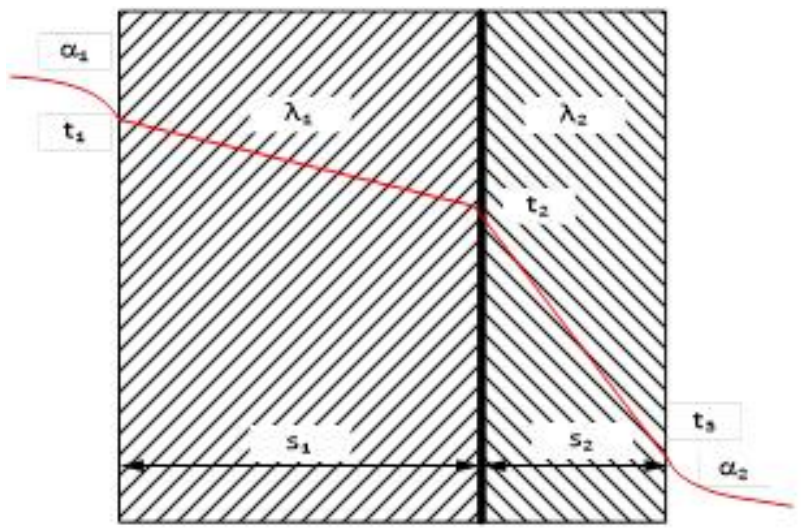

Figure 4. Lining heat losses.

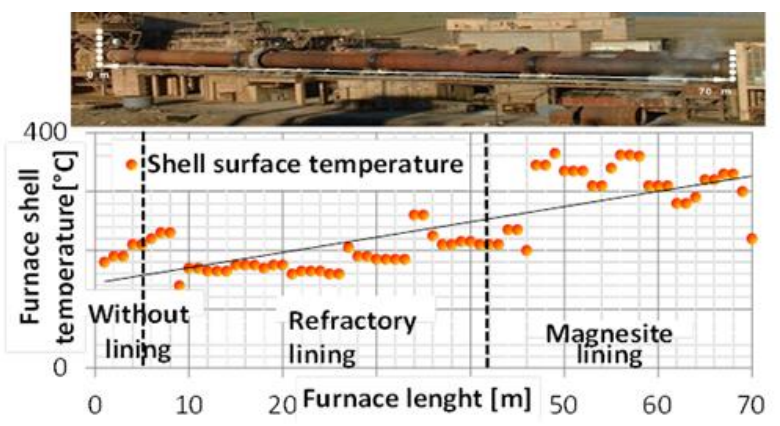

FiguRE 5. The surface temperature of rotary furnace shell No. 2.

$\triangleright$ other losses (loss due to waste flue gases and solid waste heat loss, heat loss by incomplete combustion of fuel).

The flue gas waste heat loss $\left(Q_{\mathrm{FGW}}[\mathrm{W}]\right)$ is the heat content of the flue gas leaving the furnace workspace:

$$
Q_{\mathrm{FGW}}=V_{\mathrm{GAS}} c_{\mathrm{GAS}} t_{\mathrm{GAS}}
$$

where $V_{\mathrm{GAS}}$ is flue gas volume flow $\left[\mathrm{m}^{3} / \mathrm{h}\right], c_{\mathrm{GAS}}-$ medium specific heat of the flue gas $\left[\mathrm{J} \mathrm{m}^{-3}{ }^{\circ} \mathrm{C}\right], t_{\mathrm{GAS}}$ - temperature of the flue gas leaving the furnace $\left[{ }^{\circ} \mathrm{C}\right]$. The shell heat losses $\left(Q_{\mathrm{SHL}}[\mathrm{W}]\right)$ are determined by relation [5], shown in Figure 4 .

$$
Q_{\mathrm{SHL}}=\frac{S\left(t_{1}-t_{2}\right)}{\frac{1}{\alpha_{1}}+\frac{s_{1}}{\lambda_{1}}+\frac{1}{\alpha_{2}}+\frac{s_{2}}{\lambda_{2}}}
$$

where $S$ is wall surface $\left[\mathrm{m}^{2}\right], \lambda_{1,2}$ - thermal conductivity $\left[\mathrm{W} \mathrm{m}^{-1} \mathrm{~K}^{-1}\right], t_{1,2}-$ surface temperature $\left[{ }^{\circ} \mathrm{C}\right]$, $s_{1,2}-$ wall thickness of the individual layers $[\mathrm{m}]$.

\subsection{Analysis of the CURREnt state}

The heat losses through the shell of a rotary furnace are a significant proportion of the losses for rotary furnace No. 2 at SMZ Jelsava, a.s.: $14 \%$ of the total energy expenditure for the burning process. The waste heat from the rotary furnace shell has until now been used only as a secondary effect on water heating [7, 8], or for drying. Draft implementation of controlled cooling of the furnace was implemented to 


\begin{tabular}{lc}
\hline \multicolumn{2}{c}{ Input material } \\
\hline Batch & $28130 \mathrm{~kg}$ \\
Bulk density & $1600 \mathrm{~kg} / \mathrm{m}^{3}$ \\
\hline \multicolumn{2}{c}{ Output material } \\
\hline Product & $9743 \mathrm{~kg}$ \\
Flue dust & $4620 \mathrm{~kg}$ \\
\hline
\end{tabular}

\begin{tabular}{lc}
\hline \multicolumn{2}{c}{ Natural gas } \\
\hline Volume & $2774 \mathrm{~m}^{3}$ \\
Calorific value of gas & $34325 \mathrm{MJ} / \mathrm{m}^{3}$ \\
\hline
\end{tabular}

\begin{tabular}{lr}
\hline \multicolumn{2}{c}{ Output flue gases } \\
\hline Volume & $38653 \mathrm{~m}^{3}$ \\
Temperature & $516{ }^{\circ} \mathrm{C}$ \\
\hline
\end{tabular}

\begin{tabular}{lc}
\hline \multicolumn{2}{c}{ Primary air } \\
\hline Proportion & $30 \%$ \\
Volume & $8572.2 \mathrm{~m}^{3}$ \\
\hline
\end{tabular}

\begin{tabular}{lc}
\hline \multicolumn{2}{c}{ Secondary air } \\
\hline Proportion & $70 \%$ \\
Volume & $20001.8 \mathrm{~m}^{3}$ \\
\hline
\end{tabular}

TABLE 1. Inputs and outputs of the reference state of RP No. 2.

\begin{tabular}{lc}
\hline Flue input & $2774 \mathrm{~m}^{3} / \mathrm{h}$ \\
Layer thickness & $30 \mathrm{~cm}$ \\
Flame length & $15 \mathrm{~m}$ \\
Furnace performance & $9.81 \mathrm{t} / \mathrm{h}$ \\
Furnace shell heat losses & $13.46 \mathrm{GJ} / \mathrm{h}$ \\
\hline
\end{tabular}

TABle 2. Parameters of the simulation model.

improve the operational, economic and environmental indicators in the production of sintered magnesite in rotary furnaces. The operating conditions were used for a simulation model (Table 1).

On the basis of the surface temperature of the rotary furnace shell, it was possible to determine the quantity of heat escaping from the shell of the furnace (Figure 5). The heat of the shell along the length of the furnace was inhomogeneous due to changes, such as: changes in lining thickness, a change in the lining material, the thickness and the quality of the batch 912 .

On the basis of a computer simulation (Table 2), Figure 6 shows the generated progress of temperatures for the flue gas and the material passing through the rotary furnace shell along the rotary furnace.

The value for the heat input into the process and the amount of heat rejection are shown in Table 3

The simulations (Figure 7) show that the shell losses are $14 \%$ of the total heat rejection. Heat loss from the shell therefore has a great effect on the economic and environmental indicators.

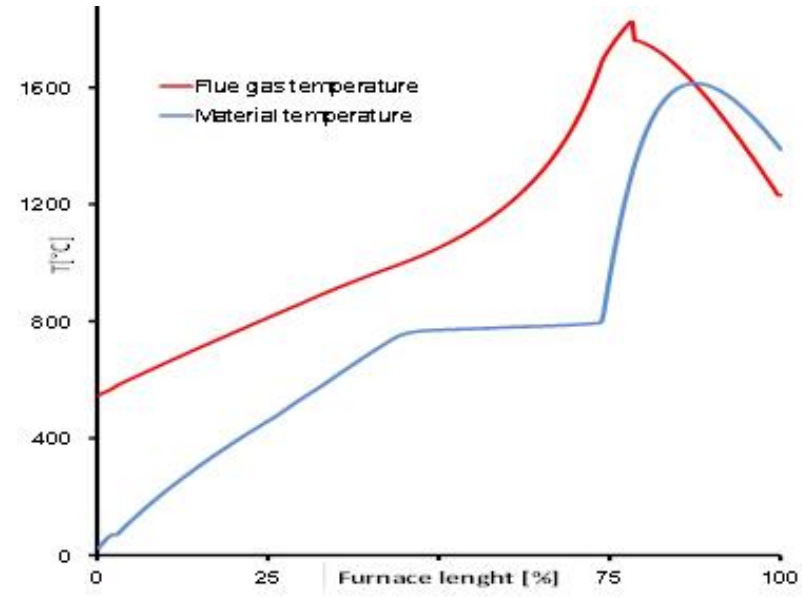

FiguRE 6. Simulation of the reference state of rotary furnace No. 2 .

\begin{tabular}{lrc}
\hline \multicolumn{1}{c}{ Detained heat } & \multicolumn{1}{c}{$[\mathrm{MJ}]$} & \multicolumn{1}{c}{$[\%]$} \\
\hline $\mathrm{Q}$ material $\mathrm{ln}$ & 508 & 0.53 \\
$\mathrm{Q}$ medium ln & 518 & 0.54 \\
$\mathrm{Q}$ burner & 95335 & 98.84 \\
Sum & $\mathbf{9 6 3 6 1}$ & $\mathbf{1 0 0}$ \\
\hline \multicolumn{1}{c}{ Escaped heat } & {$[\mathrm{MJ}]$} & \multicolumn{1}{c}{$[\%]$} \\
\hline $\mathrm{QH}_{2} \mathrm{O}$ evaporated & 654 & 0.68 \\
$\mathrm{Q}$ decomposition $\mathrm{MgCO}_{3}$ & 31308 & 32.45 \\
$\mathrm{Q}$ decomposition $\mathrm{CaCO}_{3}$ & 2498 & 2.58 \\
$\mathrm{Q}$ decomposition $\mathrm{FeCO}_{3}$ & 453 & 0.47 \\
$\mathrm{Q}$ medium Out & 35485 & 36.78 \\
$\mathrm{Q}$ material Out & 12632 & 13.09 \\
$\mathrm{Q}$ furnace shell losses & 13460 & 13.95 \\
Sum & $\mathbf{9 2 4 8 4}$ & $\mathbf{1 0 0}$ \\
\hline
\end{tabular}

TABle 3. Thermal balance of RP No. 2.

\section{A Controlled Shell COOLING SYSTEM FOR A ROTARY FURNACE (CCSRF)}

CCSRF (Figures 8 and 9p consists of the shell of the furnace, which is installed on the original shell. Between the original shell and the installed shell there is an air gap, which passes through the cooling air and removes heat from the the shell of the rotary furnace. Controlled cooling removes heat from the furnace shell, so that its temperature reaches the value of the maximum operating temperature of the material properties of the shell. The carbon steel shell can have a maximum shell temperature of $350^{\circ} \mathrm{C}$ on the surface. For steel alloys, the temperature can reach values up to approx. $600{ }^{\circ} \mathrm{C}$. By raising the temperature from the outside of the shell in this way, the temperature gradient in the furnace wall is reduced (the difference between the surface internal temperature and the temperature of the outer shell of the furnace), thereby reducing the heat flow through the furnace shell, which is the own heat loss. The reduced heat losses increase 

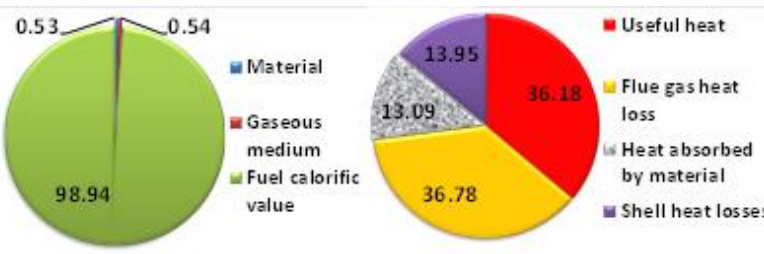

FiguRE 7. Heat balance of the reference state of rotary furnace No. 2.
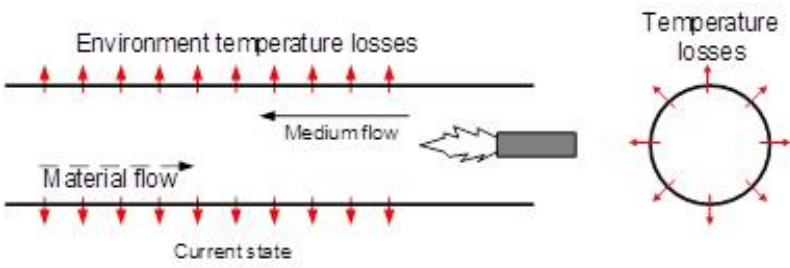

FiguRE 8. The current rotary furnace.

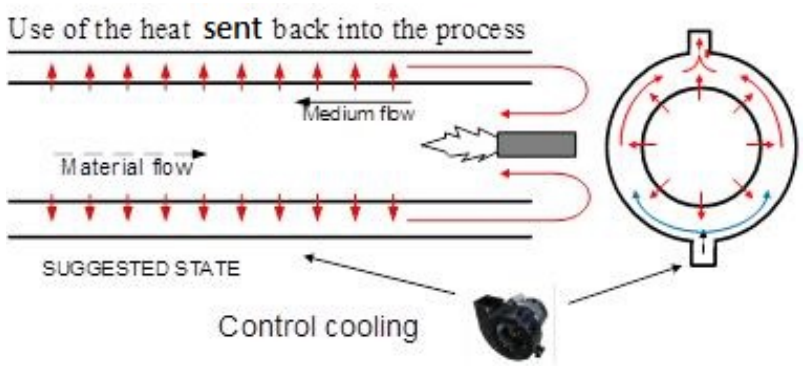

FIGURE 9. Rotary furnace with controlled shell cooling.

the useful heat [13-17].

The gaseous medium enters into the cooled shell, in which heat is transferred to the inner wall of the furnace. From the burner, the heat proceeds by radiation and convection to the lining layer and to the batch layer. The heat passes over the lining on the inner surface of the shell, where it is transferred by conduction and the lining transfers it to the surroundings. After installing the double shell, the inner shell furnace transmits heat by radiation and convection of the sampled air. The heated air is carried by convection from the outer surface of the inner shell and from the inner surface of the double shell (Figure 10.

For the heat flow $(\mathrm{Q}[\mathrm{K}])$ of the stream (convection) from the inner environment at temperature t1 to the lining surface at temperature $t_{s 1}$ is valid [15, 18, 19]:

$$
Q=\alpha_{1} \cdot S \cdot\left(t_{1} \cdot t_{s 1}\right)
$$

where $\alpha_{1}$ is heat transfer coefficient $\left[\mathrm{W} \cdot m^{-2} \cdot K^{-1}\right], S$ - surface of the shell $\left[m^{2}\right], t_{1}$ - flue gas temperature $\left[{ }^{\circ} \mathrm{C}\right], t_{s 1}$ - inner surface of the lining temperature $\left[{ }^{\circ} \mathrm{C}\right]$. The heat transfer $(\mathrm{Q}[\mathrm{W}])$ from the inner environment by radiation to the lining is determined by the relationship:

$$
Q=c S\left[\left(\frac{t_{1}}{100}\right)^{4}-\left(\frac{t_{s 1}}{100}\right)^{4}\right]
$$

where $S$ - surface of the shell $\left[\mathrm{m}^{2}\right], t_{1}$ - flue gas temperature $\left[{ }^{\circ} \mathrm{C}\right], t_{s 1}$ - inner surface of the lining temperature

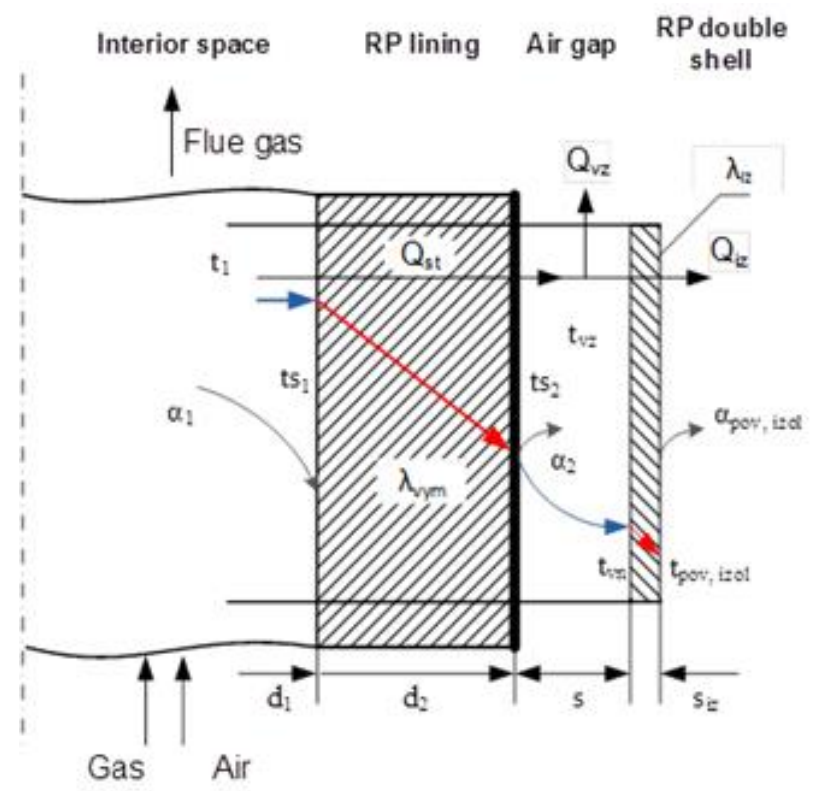

Figure 10. The principle of controlled shell furnace cooling.

$\left[{ }^{\circ} \mathrm{C}\right]$. The heat flow $(Q[\mathrm{~W}])$ led through the lining is expressed in the equation for heat conduction through a multilayer wall. For each layer:

$$
Q=\frac{2 \phi \lambda l}{\ln \frac{r_{2}}{r_{1}}}\left(t_{s 1}-t_{s 2}\right)
$$

where $t_{s 1}$ - inner surface of the lining temperature $\left[{ }^{\circ} \mathrm{C}\right], t_{s 2}$ - surface of the shell temperature RP $\left[{ }^{\circ} \mathrm{C}\right]$, $\lambda$ - thermal conductivity of the lining $\left[\mathrm{W} \cdot \mathrm{m}^{-1} \cdot K^{-1}\right.$, $r_{1,2}$ - radius (indoor, outdoor) [m], l - length of the measured part $[\mathrm{m}]$. The relationship for the convection of heat flow $(\mathrm{Q}[\mathrm{W}])$ from the RP shell surface into the surroundings is:

$$
Q=\alpha_{2} S\left(t_{s 2}-t_{2}\right)
$$

where $\alpha_{2}$ - heat transfer coefficient $\left[\mathrm{W} \mathrm{m}^{-2} \mathrm{~K}^{-1}\right], S$ - surface of the shell $\left[\mathrm{m}^{2}\right], t_{2}$ - flue gas temperature $\left[{ }^{\circ} \mathrm{C}\right], t_{s 2}$ - inner surface of the lining temperature $\left[{ }^{\circ} \mathrm{C}\right]$. To calculate the heat loss $(Q[\mathrm{~W}])$ through the wall of the rotary furnace:

$$
Q=\frac{2 \phi \lambda l}{\frac{1}{\alpha_{1}}+\ln \frac{r_{2}}{r_{1}}+\frac{1}{\alpha_{2}}}\left(t_{s 1}-t_{s 2}\right)
$$

where $\alpha_{1}$ - heat transfer coefficient from the surface to the surroundings $\left[\mathrm{W} \mathrm{m}^{-2} \mathrm{~K}^{-1}\right], \alpha_{2}$ - heat transfer coefficient $\left[\mathrm{W} \mathrm{m}^{-2} \mathrm{~K}^{-1}\right], t_{1}$ - flue gas temperature $\left[{ }^{\circ} \mathrm{C}\right], t_{2}-\mathrm{RP}$ ambient temperature $\left[{ }^{\circ} \mathrm{C}\right], r_{1,2}$ - radius (indoor, outdoor) $[\mathrm{m}]$. Shell waste heat in the form of pre-heated combustion air can be used by:

- increasing the flame temperature, which causes:

$\triangleright$ an increase in heat transfer,

$\triangleright$ an increase in the sintering temperature,

$\triangleright$ an increase in the quality of the burned clinker. 


\begin{tabular}{lc} 
Flue input & $2550 \mathrm{~m}^{3} / \mathrm{h}$ \\
Layer thickness & $30 \mathrm{~cm}$ \\
Flame length & $15 \mathrm{~m}$ \\
Furnace performance & $9.81 \mathrm{t} / \mathrm{h}$ \\
Furnace shell heat losses & $4.83 \mathrm{GJ} / \mathrm{h}$ \\
Heat returned to the process & $5 \mathrm{GJ} / \mathrm{h}$ \\
\multicolumn{2}{c}{ through the primary air } \\
\hline
\end{tabular}

TABLE 4. Simulated process parameters.

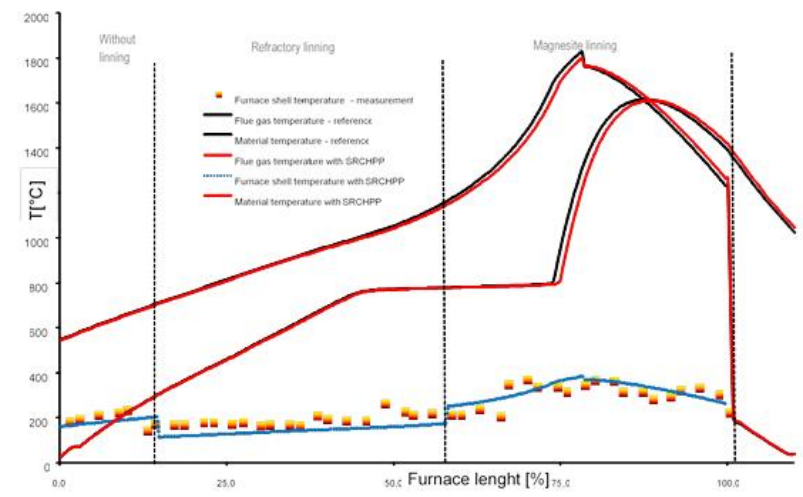

Figure 11. Simulation model of rotary furnace No. 2 with CCSRF.

- reduction of losses causes:

$\triangleright$ an increase in useful heat,

$\triangleright$ an increase in the capacity of the furnace,

$\triangleright$ an increase in the quality of the sintering.

\subsection{Simulation of the APPlication of CCSRF TO ROTARY FURNACE NO. 2}

A computer simulation (Table 4 ) generated the temperatures of the combustion gases and the material passing through the rotary furnace, and also the temperature along the course of the rotary furnace shell (Figure 11) compared to the reference state (Table 3).

Controlled cooling achieved (Table 5 , Figure 12 ) a reduction in fuel consumption of $2.774 \mathrm{~m}^{3} / \mathrm{h}$ to 2550 $\mathrm{m}^{3} / \mathrm{h}$ (natural gas), which represents a saving of $8 \%$ with unchanged performance of 9.81 tons/hour. The heat loss of the rotary furnace shell decreased from $13.46 \mathrm{GJ} / \mathrm{h}$ to $4.83 \mathrm{GJ} / \mathrm{h}$. $5 \mathrm{GJ} / \mathrm{h}$ of heat can be used for heating the combustion air. Preventing heat loss by installing a double shell will increase the useful heat value by $1.54 \%$, which means an increase in the efficiency of magnesite clink firing (Table 6).

\section{Discussion}

In magnesite sintering, the clinker quality is determined by the beginning of calcination, the completion of calcination and the maximum calcination temperature. Cooling treatment in the furnace can thereby influence the process of decomposition and sintering (speed up/slow down). By the intensity of the controlled shell cooling we can affect the flow of useful heat in the RP segment and thus control the intensity

\begin{tabular}{|c|c|c|}
\hline Detained heat & {$[\mathrm{MJ}]$} & {$[\%]$} \\
\hline Q material $\ln$ & 508 & 0.54 \\
\hline $\mathrm{Q}$ medium $\ln$ & 518 & 0.55 \\
\hline $\begin{array}{l}\text { Q brought from furnace shell } \\
\text { through primary air }\end{array}$ & 5000 & 5.34 \\
\hline Q burner & 87600 & 93.56 \\
\hline Sum & 93626 & 100 \\
\hline Escaped heat & {$[\mathrm{MJ}]$} & {$[\%]$} \\
\hline $\mathrm{QH}_{2} \mathrm{O}$ evaporated & 654 & 0.71 \\
\hline Q decomposition $\mathrm{MgCO}_{3}$ & 31304 & 33.82 \\
\hline $\mathrm{Q}$ decomposition $\mathrm{CaCO}_{3}$ & 2498 & 2.70 \\
\hline $\mathrm{Q}$ decomposition $\mathrm{FeCO}_{3}$ & 453 & 0.49 \\
\hline Q medium Out & 34934 & 37.74 \\
\hline Q mematerial Out & 12890 & 13.93 \\
\hline Q furnace shell losses & 4825 & 5.21 \\
\hline $\begin{array}{l}\text { Q brought from furnace shell } \\
\text { through primary air }\end{array}$ & 5000 & 5.40 \\
\hline Sum & 92558 & 100 \\
\hline
\end{tabular}

TABLE 5. Heat balance of RP No. 2 .
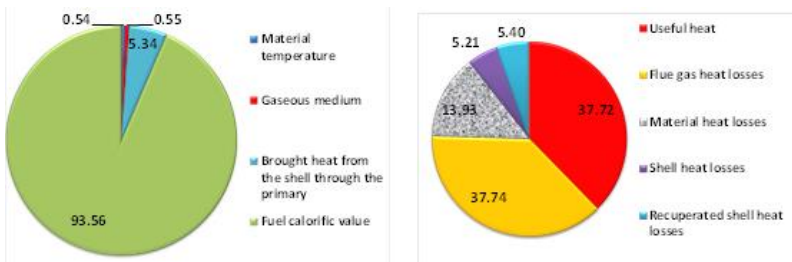

FIGURE 12. Heat balance after installation of CCSRF.

of the thermal processes taking place in the furnace. Controlled shell furnace cooling provides a new way to manage processes in a furnace, which can contribute significantly to achieving the required criteria for the processes taking plane in the rotary furnace.

\section{Conclusions}

The effect of the proposed system of controlled shell furnace cooling has been verified by simulations on a mathematical model. The proposed innovative measure fulfills the defined basic objectives of rotary furnace optimization primarily by:

- minimizing the total cost of magnesite clinker in a rotary furnace. The cost of burning to produce one ton of clinker is reduced by $7 \%$,

- increasing the immediate enforcement of the rotary furnace by increasing the theoretical combustion temperature by about $8 \%$, or

- reducing the energy consumption for magnesite clinker burning, reducing the specific fuel consumption by approx. $8 \%$,

- ensuring the temperature for furnace shell monitoring,

- increasing the preheating of the primary air and gas to the burner, 


\begin{tabular}{lcc}
\hline \multicolumn{1}{c}{ Alt. } & \multicolumn{1}{c}{$\mathbf{1}$} & $\mathbf{2}$ \\
\hline Power consumption & $2774 \mathrm{~m}^{3} / \mathrm{h}$ & $2550 \mathrm{~m}^{3} / \mathrm{h}$ \\
Performance & $9.81 \mathrm{t} / \mathrm{h}$ & $9.81 \mathrm{t} / \mathrm{h}$ \\
Specific consumption & $282 \mathrm{~m}^{3} / \mathrm{h}$ & $259 \mathrm{~m}^{3} / \mathrm{h}$ \\
Material temp. & $1615^{\circ} \mathrm{C}$ & $1610^{\circ} \mathrm{C}$ \\
Flue gas temp. & $1825^{\circ} \mathrm{C}$ & $1796{ }^{\circ} \mathrm{C}$ \\
Savings & - & $8 \%$ \\
\hline & Reference & $\mathbf{C C S R F}$ \\
\hline
\end{tabular}

TABLE 6. Comparison of reference and proposed status.

- reducing the consumption of combustion air, and thereby reducing the emissions of $\mathrm{CO}_{2}, \mathrm{NO}_{x}$.

The analysis of the impact of CCSRF on the technological process and on the economics of the innovation demonstrated the usefulness of this measure. The proposed solution is based on self-regulatory principles and provides a significant opportunity to improve the operation of rotary furnaces. The proposed solution gained heat used directly in the technological process of the rotary furnace and also created synergies with other measures (the diffusion burner, the self-batch feeder, the rolling rotary furnace sealing). By combining these measures it is possible to achieve fuel savings of about $30 \%$.

\section{ACKNowledgements}

"This paper is the result of the project under the title Development of a joint research and development and innovation centre and streamlining its use in thermal processing of raw materials, supported by the Research \& Development Operational Programme funded by the ERDF (ITMS: 26220220151).

\section{REFERENCES}

[1] J. Mikula. Mathematical modelling of thermal processes for virtual reality environment. Dissertation thesis, TU, Kosice, Slovakia, 2009.

[2] F. T. J. Staron. Refractory materials-productions, properties and usage. Second printing. Radovan Mlynarik-MEDIA, Banska Bystrica, Slovakia, 2000.

[3] FEECO Int. Rotary kiln refactory. Photo [2014-12-01], http://www.flickr.com/photos/68660976@N06/ 6322419239

[4] A. Varga. Thermal technology in metallurgy. First printing. Technical University, Kosice, Slovakia, 1999.
[5] H. Brunklaus. Construction of industry furnaces. First printing. State publishing technical literature, Praha, Czechoslovakia, 1966.

[6] V. Vitek. Industry furnaces II. First printing. Slovak publishing technical literature, Bratislava, Czechoslovakia, 1965.

[7] P. S. A. Caputo, P. Pelagagge. Performance modeling of radiant heat recovery exchangers for rotary kilns. Applied Thermal Engineering 31(14-15):2578-2589, 2011. DOI:10.1016/j.applthermaleng.2011.04.02

[8] J. S. J. Lisuch. Technological logistic - innovative trend in rotary furnaces. 5th International Conference LOADO 2009 - Logistics and Transport, Strbske Pleso, Slovakia, ISSN: 1451-107X pp. 139-143, 2009.

[9] J. S. J. Lisuch, J. Mikula. Rotary kiln shell controlled cooling system. ICCC' 2007 : Proceedings of 8th International Carpathian Control Conference, High Tatras, Slovak Republic pp. 426-429, 2007.

[10] M. R. et al. Thermal calculations and optimization lining of industrial furnaces. Publishers of technical literature SNTL, Praha, CzechoSlovakia, 1975.

[11] K. Michalikova-Frajtova. Effective process management in the conditions of globalization. Logistic monitor, Rajecke Teplice, Slovakia, ISBN: 979-80-969745-1-0 pp. 126-132, 2008.

[12] B. Chakrabarti. Investigations on heat loss through the kiln shell in magnesite dead burning process: a case study. Applied Thermal Engineering 22(12):1339-1345, 2002. DOI:10.1016/S1359-4311(02)00051-0

[13] K. Z. J. Herman, M. Hezina. Industrial innovations. First printing. Economic university Praha, Praha, 2002.

[14] A. R. J. Spisak, J. Lisuch. Technological logistics tool of optimalization of heat treatment processes of raw materials. Metal 2011 : 20th Anniversary International Conference on Metllurgy and Materials, Brno, Czech Republic, ISBN: 978-80-87294-24-6 pp. 1-8, 2011.

[15] J. Terpak. Modelling and control of technological processes. Habilitation thesis, TU, Kosice, Slovakia 2002.

[16] M. Michejev. Fundamentals of Heat sharing. Second printing. Industrial publishing, Praha, CzechoSlovakia, 1953.

[17] I. I. L. Komorova. Thermodynamics in metallurgy. Alfa, Bratislava, Slovakia, ISBN: 800501077X, 1992.

[18] I. Kostial. Lectures on modeling and simulation of technological processes. Kosice, TU, Slovakia 1998.

[19] L. Kuna. Refractory linings of industrial furnaces. First printing. Slovak publishing technical literature, Bratislava, Czechoslovakia, 1967. 